\title{
Conditions influencing the choice between direct shipment and transshipment in maritime shipping network
}

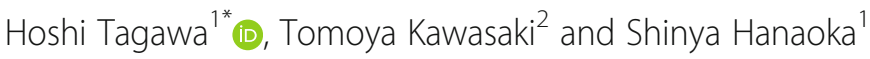

\author{
* Correspondence: tagawa.h.ab@m. \\ titech.ac.jp \\ ${ }^{1}$ Department of Transdisciplinary \\ Science and Engineering, Tokyo \\ Institute of Technology, Tokyo, \\ Japan \\ Full list of author information is \\ available at the end of the article
}

\begin{abstract}
This study examines the conditions that influence the choice between direct shipment and transshipment, focusing on two factors: geographical distance and demand. We develop a two-stage model comprising shipping lines and shippers, and apply it to a virtual maritime network with one origin, two destination ports, and one hub port. The generalized costs of shippers in the optimum direct shipment and in transshipment for the shipping lines model are compared to evaluate the choice between direct shipment and transshipment. We find that competitiveness of the port as a hub, indicating the cargo volume aggregated in transshipment, is essential for examining the cost-effectiveness of direct shipment and transshipment. The comparison between the cost-effectiveness of direct shipment and transshipment is based on the configuration of each network, especially in terms of frequency and the vessel size deployed. Direct shipment can be more cost-effective for short distances.
\end{abstract}

Keywords: Shipping network, Direct shipment, Transshipment, Two-stage model

\section{Introduction}

Maritime shipping networks comprise two types of transport systems: direct shipment and transshipment. As the term suggests, direct shipment involves a carrier transporting cargo from the origin to destination using a single service. In transshipment, the carrier transports cargo from the origin to destination by combining multiple services. Specifically, the carrier aggregates several services in an intermediate port, called a hub, and transports the cargo via this hub, combining the appropriate services. As transshipment cargo needs to be transported via one or more additional ports to arrive at the destination port, it involves additional navigation distance, navigation time, port charges, and stevedoring charges (Hsu and Hsieh 2005). Conversely, the number of shipping services required to connect all points of origin and destination in transshipment is fewer than in direct shipment. Fewer shipping services reduce the network construction cost (O’Kelly and Miller 1994). Notteboom et al. (2019) found that the volatility of ports that largely handle direct shipment cargo differs from that of ports that largely handle transshipment cargo. Thus, distinguishing between direct shipment

(c) The Author(s). 2021 Open Access This article is licensed under a Creative Commons Attribution 4.0 International License, which permits use, sharing, adaptation, distribution and reproduction in any medium or format, as long as you give appropriate credit to the original author(s) and the source, provide a link to the Creative Commons licence, and indicate if changes were made. The images or other third party material in this article are included in the article's Creative Commons licence, unless indicated otherwise in a credit line to the material. If material is not included in the article's Creative Commons licence and your intended use is not permitted by statutory regulation or exceeds the permitted use, you will need to obtain permission directly from the copyright holder. To view a copy of this licence, visit http://creativecommons.org/licenses/by/4.0/. 
and transshipment can enable port management bodies (i.e., port authorities) to design their port strategies.

Wilmsmeier and Notteboom (2011) revealed the importance of cargo demand in determining whether to implement direct shipment or transshipment. When cargo demand is high enough to justify direct calls to ports, the ratio of transshipment declines. In fact, the ratio of direct shipment between Shanghai port and Japanese ports, considered short-distance trade (as the distance between Shanghai and Tokyo ports is 1021 nautical miles), is $95.9 \%$ as of November 2018 (Ministry of Land, Infrastructure, Transport and Tourism [MLIT] of Japan 2018), with Shanghai being the port with the largest trade volume to/from Japan. Thus, in high cargo demand conditions, majority of the cargo is transported through direct shipment. In contrast, some other ports with similar cargo demand have different direct shipment ratios. For example, the total cargo volumes between Xiamen, Vancouver, and Rotterdam ports, and Japanese ports are almost equal-as of November 2018-at 241588 freight tons, 305,375 freight tons, and 298,000 freight tons, respectively (Ministry of Land, Infrastructure, Transport and Tourism (MLIT) of Japan 2018). However, the direct shipment ratios between these three ports and Japanese ports are 92.2\%, 77.2\%, and 64.5\%, respectively (Ministry of Land, Infrastructure, Transport and Tourism (MLIT) of Japan 2018). Note that the distance from Xiamen, Vancouver, and Rotterdam ports to Tokyo port is 1328 nautical miles (nm), $4324 \mathrm{~nm}$, and $11,119 \mathrm{~nm}$, respectively. The differences in the ratios of direct shipment and transshipment can be observed by comparing the pairs of trading ports. Thus, it is evident that factors other than cargo demand, such as different geographical conditions, influence the choice between direct shipment and transshipment.

Although literature on direct shipment and transshipment exists, few studies consider both these systems of maritime transport. Hsu and Hsieh (2005) analyze the trade-off between shipping and inventory costs in direct shipment and transshipment. Direct shipment is more cost-effective than transshipment, given the optimum vessel size and frequency in high cargo demand. Wilmsmeier and Notteboom (2011) identify four phases of network evaluation with regard to direct shipment and transshipment and find that the growth of market size of ports has caused the rise in direct services and undermining of hubs. These two studies investigate the significance of cargo demand in implementing direct shipment. However, there is a research gap in that the factors other than cargo demand that influence the comparison between direct transport and transshipment have not been analyzed.

Morrell (2008) and Francis et al. (2007) reveal that low-cost carriers implementing direct transport have a cost advantage in short-haul flights in the air transport network. Despite the differences in the network configurations of air and maritime transport, this implies that the choice between direct shipment and transshipment is influenced by geographical factors, such as distance. Several studies on maritime networks emphasize the importance of the geographical conditions of ports. For example, Chang et al. (2008) and Gohomene et al. (2016) find that shipping lines, including trunk liners and feeder service providers, consider port location a critical factor in port selection. $\mathrm{Ng}$ and Kee (2008) indicate that the optimum vessel size depends on distance, that is, larger vessels are cost-effective for longer distances. Veldman et al. (2016) proposed to address the port choice problem with a logit model based on maritime distance and vessel size. Sun and Zheng (2016) and Notteboom (2011) discuss the appropriateness 
of a hub location. Kavirathna et al. (2018) reveal that Colombo port lacks competitiveness as a hub in relay networks, due to geographical conditions such as deviation from the trunk line.

Thus, although cargo demand and geographical conditions are important in determining whether to implement direct shipment or transshipment, the conditions in which these factors affect the choice are unclear. Therefore, this study aims to investigate the conditions influencing the choice between direct shipment and transshipment, focusing on two factors: geographical distance and demand.

When designing maritime network, shipping lines consider a trade-off between the requirements of shippers and own operational cost (Ducruet and Notteboom 2012; Wang et al. 2015; Hsu and Hsieh 2005). The operation of direct shipment or transshipment can be affected by the cost of shipping lines and shippers. Thus, this study developed the two-stage model between shipping lines and shippers. In this model, shipping lines deploy the optimum vessel size and frequency for own cost minimization and the genialized cost of shippers is calculated based on the time cost and monetary cost. We compare the generalized cost of shippers in the optimum direct shipment and transshipment for the shipping lines by the two-stage model to evaluate the choice between direct shipment and transshipment. The developed two-stage model is applied to simplified virtual network. We change the cargo demand and geographical conditions between ports in the virtual network. Note that we focus on the analysis of the factors such as cargo demand and geographical conditions. However, other factors that might affect the choice between direct shipment and transshipment such as marketing efforts, schedule design and service quality of ports are not considered.

The remainder of this paper is structured as follows. Methodology section presents the methodology used in this study. Numerical analysis and results section discusses the numerical analysis and results of applying the developed model to a virtual network. Conclusions section states the conclusions drawn from the study findings and offers directions for further research.

\section{Methodology}

\section{Model development}

This study uses a two-stage model comprising shipping lines and shippers. As decisionmakers in the upper stage, shipping lines design two different networks comprising one service for direct shipment and multiple services for transshipment. In the lower stage, the shippers' generalized cost for direct shipment and transshipment is calculated. The notations of the model are as follows:

\footnotetext{
i,j Port name $(i \neq j, i, j \ni 0$ : origin, $h$ : hub, and $d$ : destination)

$k \quad$ Name of the transport system (DR: direct shipment or TS: transshipment)

$G C_{i j}^{k}$ Generalized cost of the shippers using transport system $k$ from port $i$ to $j$ [USD/TEU (20-ft equivalent unit)]

$C_{i j} \quad$ Cost of the shipping lines from port $i$ to $j$ [USD/month]

$v c_{i j} \quad$ Vessel costs (capital and operating costs) from port $i$ to $j$ [USD/day]

$f c_{i j} \quad$ Fuel cost for transport from port $i$ to $j$ [USD/day]

$p c_{i} \quad$ Port charges for transport from port $i$ to $j$ [USD/time]

$h c_{i} \quad$ Handling charges in port $i$ [USD/TEU]

$f_{i j} \quad$ Frequency from port $i$ to $j$ [time/month]
} 
Model development (Continued)

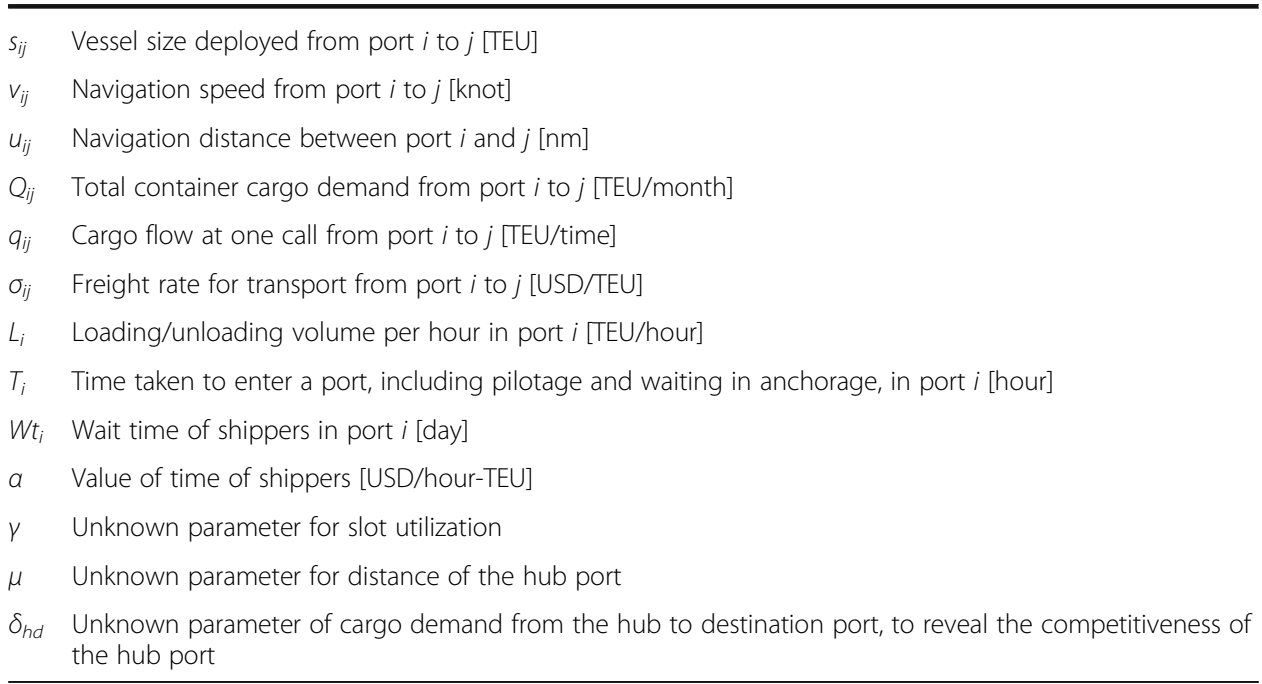

\section{Shipping lines}

The behavior of shipping lines as carriers is characterized by a model with the objective of maximizing their own profit. The freight rate to shippers, comprising the main revenue component for shipping lines, is influenced by several market factors, such as competition between services operated by different carriers. This study assumes strong competition between shipping lines, leading to lower freight rates, and diminishing the differences in freight rates among shipping lines. For maximizing their profit, shipping lines need to minimize the cost of each service. Therefore, in this study, the shipping lines' objective is to minimize their own cost for the given inputs. The shipping lines determine the vessel size $\left(s_{i j}\right)$, vessel speed $\left(v_{i j}\right)$, and frequency $\left(f_{i j}\right)$ for each route (from port $i$ to $j$ ). Equation (1) expresses the shipping lines' cost, calculated as the product of the frequency of calls and the operation cost per call.

According to Hsu and Hsieh (2007), operation cost comprises three elements: capital and operating costs, fuel cost, and port charges. Capital and operating costs include the total expenses paid for vessel operation each day. We renamed them vessel costs $\left(v c_{i j}\right)$ in this study, comprising the cost of chartering the vessel and operating costs, including maintenance, repair costs, and so on. The shipping lines incur the vessel costs for the total voyage time that includes navigation time, expressed as the relationship between navigation distance and navigation speed $\left(u_{i j} / v_{i j}\right)$, the time taken for loading or unloading in the port $\left(q_{i j} / L_{i}\right)$, and the time taken to enter the port, including pilotage and waiting in anchorage $\left(T_{i}\right)$. Fuel cost $\left(f_{i j}\right)$ comprises the expense related to fuel consumption. Wang and Meng (2012) conclude that fuel consumption is the third power of navigation speed. We multiply the fuel consumption by navigation time to take the sailing time into consideration. Port charges can be categorized into the charges for the vessel and for handling cargo. In this study, the former is termed port charges $\left(p c_{i}\right)$ and comprises the charges for servicing the vessel-including, for example, pilotage and towage-paid twice, that is, at the origin and destination port. The latter is termed handling charges $\left(h c_{i}\right)$, paid for handling cargo in the container yard, and charged per container. Thus, we calculate the handling charges per call $\left(q_{i j}\right)$. 
There are two constraints. First, per eq. (2), the vessel capacity of the shipping lines exceeds total cargo demand $\left(Q_{i j}\right)$. Parameter $(\gamma)$ representing slot utilizations is set based on Wang and Meng (2012), as described in Input Values and Network Conditions section. Equation (3) indicates that the cargo volume at one port of call is calculated based on the total cargo volume and frequency. Parameter $\left(\delta_{h d}\right)$ expresses the aggregated cargoes with the same destination but different origins, in the hub port. For example, if parameter $\delta_{h d}$ equals one, there are no services from the hub to destination port without a simulation target origin-destination (OD) pair. If parameter $\delta_{h d}$ equals five, then four times the cargo volume between the simulation target OD pair is aggregated in the hub port, to transport five times the cargo volume. Additionally, this parameter indicates the port's competitiveness as a hub, because a larger hub port would aggregate more cargo, thus expressing a larger value. We can simulate the effects of the differences in port competitiveness by modifying this parameter.

$$
\min _{f_{i j}, s_{i j}, v_{i j}} C s_{i j}=f_{i j}\left(v c_{i j}\left(T_{i}+q_{i j} / L_{i}+u_{i j} / v_{i j}+T_{j}+q_{i j} / L_{j}\right)+f c_{i j} v_{i j}^{3} u_{i j} / v_{i j}+p c_{i}+p c_{j}+\left(h c_{i}+h c_{j}\right) q_{i j}\right)
$$

subject to:

$$
\begin{aligned}
& \gamma \cdot f_{i j} \cdot s_{i j} \geq Q_{i j} \\
& q_{h d}=\delta_{h d} \cdot Q_{o d} / f_{h d}
\end{aligned}
$$

Second, vessel costs, fuel cost, and port charges depend on the vessel size, and are calculated using eqs. (4), (5), and (6), respectively. The coefficients of these equations are estimated in previous studies (Tran 2011; Kim et al. 2019), using several methods, including the least squares method based on actual data of container vessels. The term $B P$ in eq. (4) indicates the bunker price, set at $387.5 \mathrm{USD} /$ ton, indicating the average in 20 major global ports from July 31, 2018 to August 29, 2019, sourced from Ship and Bunker (2019).

$$
\begin{aligned}
f c_{i j} & =B P \cdot\left(0.0392 \cdot s_{i j}+5.582\right) /\left(5.4178 \cdot s_{i j}^{0.1746}\right)^{3} \\
v c_{i j} & =108.05 \cdot s_{i j}^{0.6257}+1.4095 \cdot s_{i j}+6125.9 \\
p c_{i j} & =0.3936 \cdot\left(12.556 \cdot s_{i j}+1087.2\right)+5356
\end{aligned}
$$

\section{Shippers}

In this study, we calculate the generalized cost per TEU of shippers, to enable them to choose between direct shipment and transshipment. Equation (7) expresses the generalized cost for direct shipment. $W t_{i}$ indicates the waiting time at port $i$, such as for the customs procedure. The term $30 / 2 f_{\text {od }}$ represents the average waiting time for calling the vessel. As the unit of frequency is times per month, the number 30 is multiplied. As for denominator, the number 2 is used to calculate the average value (Wang et al. 2014). Other time-related factors considered include the navigation time and loading or unloading time. The monetary cost of shippers includes the freight rate $\left(\sigma_{i j}\right)$ calculated in eq. (8), imposed by the shipping lines. As expressed in eq. (8), the shipping lines determine the freight rate based on avoiding a deficit. The smallest 
integer value is calculated as the freight rate, exceeding the total cost by cargo demand. Equation (9) expresses the generalized cost for transshipment. The generalized cost for direct shipment includes origin to destination port, while the generalized cost for transshipment includes origin to hub port, and hub to destination port. In principle, the generalized costs for direct shipment and transshipment have the same components.

$$
\begin{aligned}
& G C_{o d}^{D R}=\alpha\left(W t_{o}+\frac{30}{2 f_{o d}}+\frac{q_{o d}}{L_{o}}+\frac{u_{o d}}{v_{o d}}+\frac{q_{o d}}{L_{d}}+W t_{d}\right)+\sigma_{o d} \\
& \sigma_{i j}=\left\{\min \sigma_{i j} \mid Q_{i j} \cdot \sigma_{i j} \geq C s_{i j}, \sigma_{i j} \in \mathbb{N}\right\} \\
& G C_{o d}^{T S}=\alpha\left(W t_{o}+\frac{30}{2 f_{o h}}+\frac{q_{o h}}{L_{o}}+\frac{u_{o h}}{v_{o h}}+\frac{30}{2 f_{h d}}+\frac{u_{h d}}{v_{h d}}+\frac{q_{h d}}{L_{d}}+W t_{d}\right)+\sigma_{o h}+\sigma_{h d}
\end{aligned}
$$

\section{Calculation flow}

In this study, we consider a virtual maritime network instead of a real one, so that we can easily modify the two factors-geographical distance and cargo demand-as illustrated in the examples in Fig. 1. The virtual network has one origin port, two destination ports, and one hub port. These are the minimum required values to investigate the influence of geographical changes in one port on another. For instance, focusing on the shipment to Destination 2 in Fig. 1, we can simulate the influence of geographical changes in Destination 1 on Destination 2, by comparing examples 1 and 2.

Figure 2 illustrates the calculation flow of this study. First, we determine the number of OD pairs and the four factors, that is, cargo demand $\left(Q_{i j}\right)$, distance $\left(u_{i j}\right)$, value of time $(\alpha)$, and bunker price $(B P)$, as inputs for the virtual maritime network. Second, we implement the two-stage model in direct shipment and transshipment separately. At the upper stage, the shipping lines decide the variables including vessel size, navigation speed, and frequency to minimize their cost in each network, as expressed in eq. (1). In transshipment, the calculations are further categorized as from origin to hub port and from hub to destination port. Theoretically, we can calculate one of the decision variables, that is, the optimum navigation speed, because the cost of the shipping lines is a concave function of the navigation speed, as expressed in eq. (1). The partial differentiation of eq. (1) can be calculated to obtain the optimum navigation speed in eq. (10). As vessel and fuel costs are positive, we can calculate the optimum navigation speed based on these costs, as expressed in eq. (11). The optimum navigation speed depends on vessel and fuel costs; especially, as fuel cost is in proportion to bunker price $(B P)$, the optimum navigation speed decrease when bunker price increase. This matches the property of the relationship between operating speed of vessels and fuel price

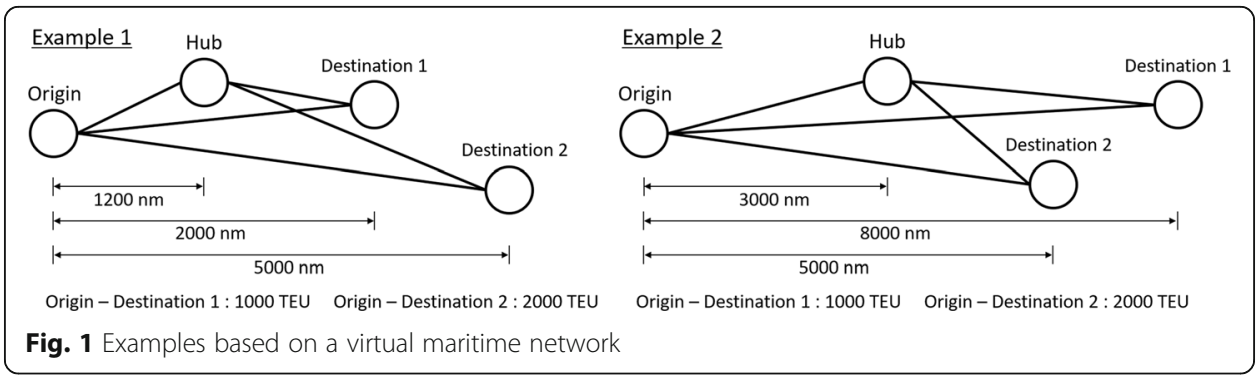




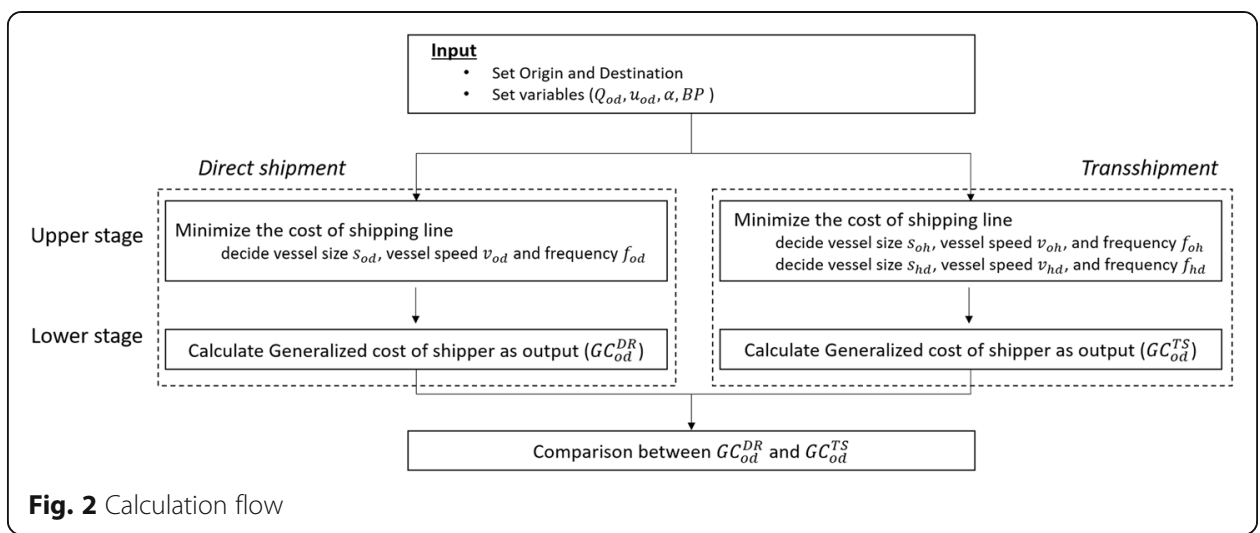

(Notteboom and Vernimmen 2009). Furthermore, as vessel and fuel costs depend on the vessel size, the optimum navigation speed also depends on it, thus enabling a direct calculation of the optimum navigation speed using the optimum vessel size. Owing to the relatively low computational complexity required to obtain optimum values of the other decision variables, including vessel size and frequency, we implement a bruteforce search as the solution algorithm.

In the lower stage, the shippers' generalized cost is calculated based on the shipping lines' decisions on vessel size, navigation speed, and frequency. Subsequently, we compare the generalized cost of each network. We compare all patterns of the inputs, such as distance and cargo demand of OD pairs, to reveal cost-effectiveness of direct shipment or transshipment. These calculations are coded in MATLAB, which is a multi-paradigm programming language and numerical computing environment, and processed on an Intel $^{\bullet}$ Core $^{\text {Tu }}$ i5-8265U processor with 8 gigabytes of random access memory.

$$
\begin{aligned}
& \frac{\partial C s_{i j}}{\partial v_{i j}}=\frac{f_{i j} u_{i j}}{v_{i j}^{2}}\left(2 \cdot f c_{i j} \cdot v_{i j}^{3}-v c_{i j}\right) \text { where } v c>0 \text { and } f c>0 \\
& v_{i j}=\left(\frac{v c_{i j}}{2 \cdot f c_{i j}}\right)^{\frac{1}{3}}
\end{aligned}
$$

\section{Numerical analysis and results}

\section{Input values and network conditions}

Several input values are required in this study. As discussed in Calculation Flow section, we set one origin port, two destination ports, and one hub port in the virtual maritime network to determine the influence of geographical changes through a simple calculation. As illustrated in Fig. 3, in this virtual network, the conditions of one of the destination ports, the focus port (Destination 2), are modified only slightly, while major changes are made to the conditions of the other destination port (Destination 1). Specifically, as expressed in eqs. (12) and (13), we modify the distance from $100 \mathrm{~nm}$ to $10,000 \mathrm{~nm}$ and cargo demand from $500 \mathrm{TEU}$ to 10,000 TEU. In each case, the distance of Destination 1 changes significantly, while cargo demand $\left(Q_{o 1}\right)$ remains constant at 2500 TEU for three cases: the short distance case $\left(u_{o 1}=2000 \mathrm{~nm}\right)$, mid distance case $\left(u_{o 1}=5000 \mathrm{~nm}\right)$, and long-distance case $\left(u_{o 1}=8000 \mathrm{~nm}\right)$. The influence of 


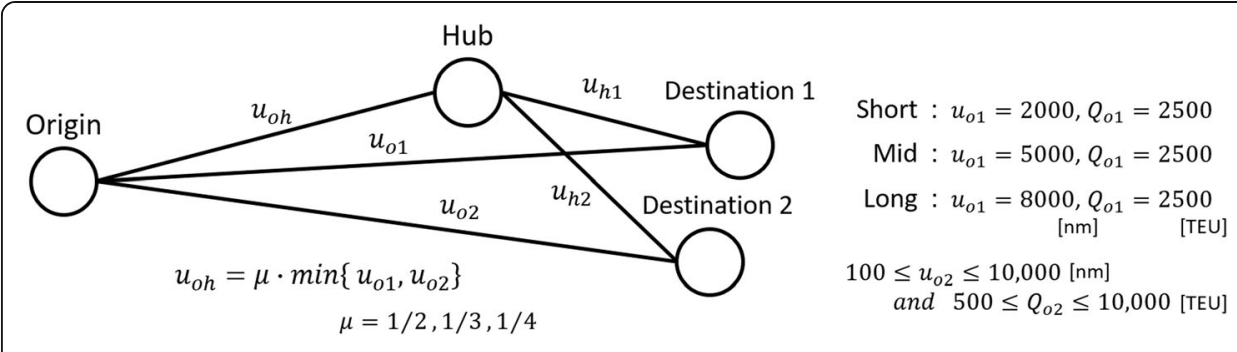

Fig. 3 Simulation network

geographical changes can be estimated by comparing these three cases. We compare the generalized cost of shippers in each combination of network conditions to identify those in which the generalized cost for direct shipment is lower than that for transshipment. Eq. (14) expresses the distance from the origin to hub port $\left(u_{o h}\right)$. We assume that the distance is determined by multiplying a parameter $\mu$ to the distance between the origin and destination port. The closer of the distances to the origin among Destinations 1 and 2 is chosen. The value of $\mu$ is set as one of three values $(1 / 2,1 / 3$, or $1 / 4)$. Shipping lines can decide on one of these to minimize their cost.

$$
\begin{aligned}
& u_{o 2}=\left\{100 \cdot n_{1} \mid 1 \leq n_{1} \leq 100, n_{1} \in \mathbb{N}\right\} \\
& Q_{o 2}=\left\{500 \cdot n_{2} \mid 1 \leq n_{2} \leq 20, n_{2} \in \mathbb{N}\right\} \\
& u_{o h}=\mu \cdot \min \left\{u_{o 1}, u_{o 2}\right\}
\end{aligned}
$$

Table 1 exhibits the other input variables and conditions in this model. We refer to Wang and Meng (2012) for estimation of handling charges $\left(h c_{i}\right)$ and to Waterfront Vitalization and Environment Research Foundation (WAVE 2011 for estimation of the value of time $(\alpha)$. We have estimated the values of other variables, such as loading/ unloading volume per hour $\left(L_{i}\right)$ by ourselves, as references are not available for them. Furthermore, shipping lines can decide on one vessel size with 15 variations, between $1000 \mathrm{TEU}$ and 15,000 TEU. In the route from the origin to hub port, it is assumed that shipping lines can choose 7 vessel types of a size between 1000 TEU and 7000 TEU, to avoid vessels that are too large for the feeder.

\section{Results}

We observe 100 cases for the distance of Destination 2 from $100 \mathrm{~nm}$ to $10,000 \mathrm{~nm}$. However, the results for distances over $3000 \mathrm{~nm}$ are identical. Thus, the results for

Table 1 Input parameters in simulation

\begin{tabular}{llllll}
\hline Parameters & & Origin & Hub & Destination & Source \\
\hline Handling charges in port $i$ [USD/TEU] & $h c_{i}$ & 60 & 100 & 60 & Estimated by the author \\
Loading/unloading volume in port $i$ [TEU/hour] & $L_{i}$ & 100 & - & 100 & Wang and Meng (2012) \\
Time taken to enter the port [hours] & $T_{i}$ & 8 & 12 & 8 & Estimated by the author \\
Shippers' waiting time in port $i$ [days] & $W t_{i}$ & 2 & - & 1 & Estimated by the author \\
Value of shippers' time [JPY/hour] & $a$ & 2200 & & WAVE (2011) \\
Parameter for slot utilization & $Y$ & 0.7 & & Estimated by the author \\
\hline
\end{tabular}


distances over $5000 \mathrm{~nm}$ are omitted from Figs. 4, 5 and 6 to improve the visibility of the figures.

\section{Cargo demand}

Figure 4 illustrates the simulation results of Destination 2, where the geographical location of Destination 2 is modified slightly to create three cases (i.e., short, mid, and long distance) in relation to Destination 1. The horizontal line indicates the distance between the origin and Destination 2, while the vertical line indicates the cargo demand from the origin to Destination 2. The dark blue cells indicate advantageous conditions for direct shipment in terms of the generalized cost of shippers.

Figure 4 reveals no prominent difference among the results of the three, that is, the short-, mid-, and long-distance cases, except for over $3000 \mathrm{~nm}$ and 3500 TEU. Thus, geographical changes in different destination ports with cargo from the same origin do not influence the shippers' generalized cost, as we calculate the shippers' generalized cost in Destination 2 based on the configuration of origin-hub and hub-Destination 2. Although the distance of Destination 1 can influence the hub position, it does not affect another important configuration, that is, the frequency of origin-hub and hub-Destination 2. Therefore, the geographical location of the other port and the cargo demand between the origin and destination ports do not influence the shippers' generalized cost in these three cases.

The results displayed in Fig. 4 confirm the two limits: 4000 TEU (cargo demand) and $2000 \mathrm{~nm}$ (distance). Relatively low cargo demand of up to 4000 TEU indicates an overall lower generalized cost for direct transport than for transshipment, although it is influenced by navigation distance as well. We observe the effect of $\left(\delta_{h d}\right)$, described in Shipping Lines Section as the parameter that expresses the aggregated cargo at the hub port of the transshipment with different origins but the same destinations as those of the focus port. We assume that the volume of aggregated cargo in the hub port for the hub-Destination 2 route depends on the cargo demand of Destination $2\left(Q_{02}\right)$. In short, the volume of aggregated cargo is small, in low demand, and with low parameter values. The economy of density, an advantage of transshipment arising from the combination of multiple services, does not apply effectively within 4000 TEU in this simulation, rendering direct shipment more cost-effective. Therefore, to observe the impact of cargo aggregation in a hub port, we consider the following two cases by modifying the volume of aggregated cargo in the short distance case: no aggregation $\left(\delta_{h d}=1\right)$ and large aggregation $\left(\delta_{h d}=10\right)$. Figure 5 illustrates the results. The vertical line indicates the number of points in which the generalized cost for direct shipment is lower than that for transshipment in 20 different cargo demand conditions from 500 TEU to 10,000 TEU. Figure 5 illustrates that in the cases in which the volume of aggregated cargoes is twice in large aggregation cases, the number of cases in which direct shipment is more cost-effective than transshipment decreases. Conversely, in the no aggregation case, transshipment is more cost-effective than direct shipment in almost all cases, because the economy of density does not apply from the hub port to the destination port effectively. Thus, there is no reason to implement transshipment if cargo aggregation does not occur in the hub port. Significantly, as the cargo is shipped simultaneously to 


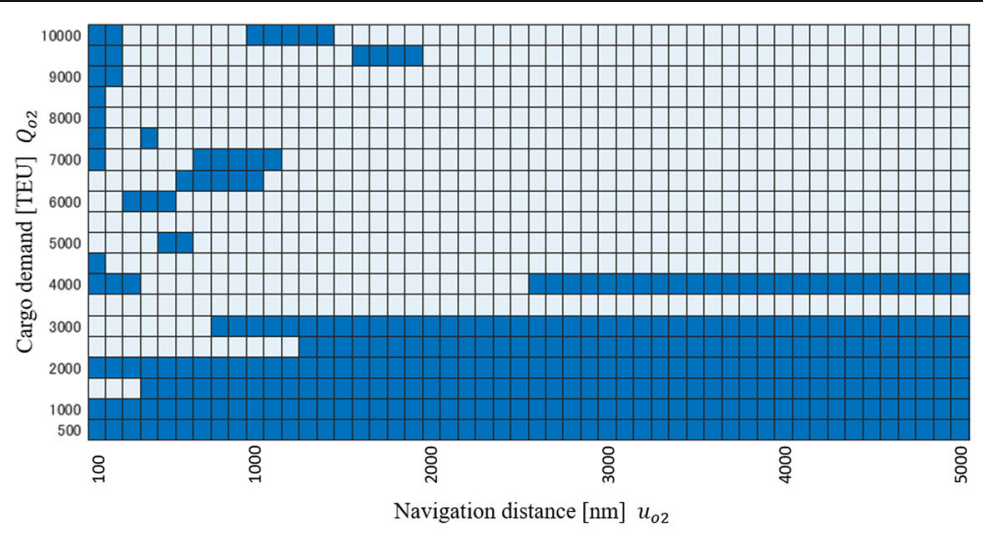

(a) Short distance case $\left(u_{o 1}=2000 \mathrm{~nm}, Q_{o 1}=2500 T E U\right), \delta_{h d}=5$

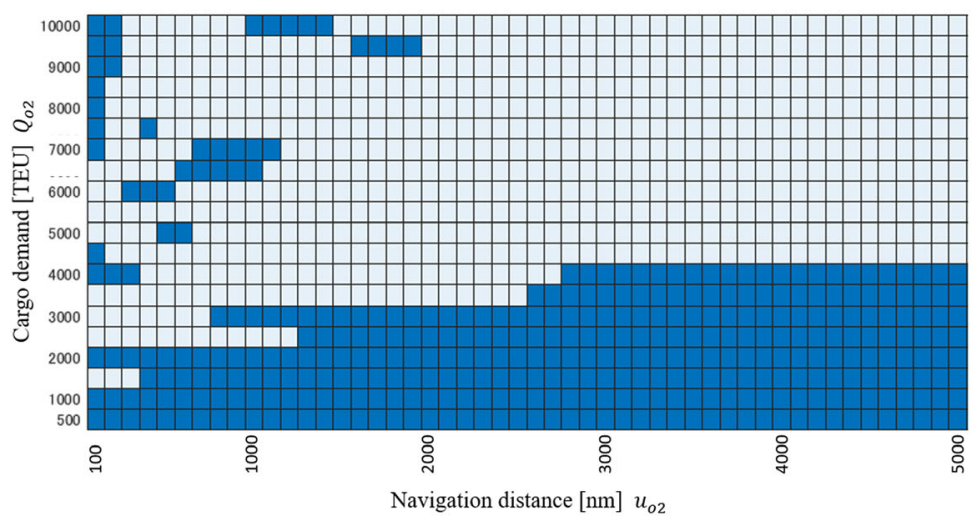

(b) Middle distance case $\left(u_{o 1}=5000 \mathrm{~nm}, Q_{o 1}=2500 \mathrm{TEU}\right), \delta_{h d}=5$

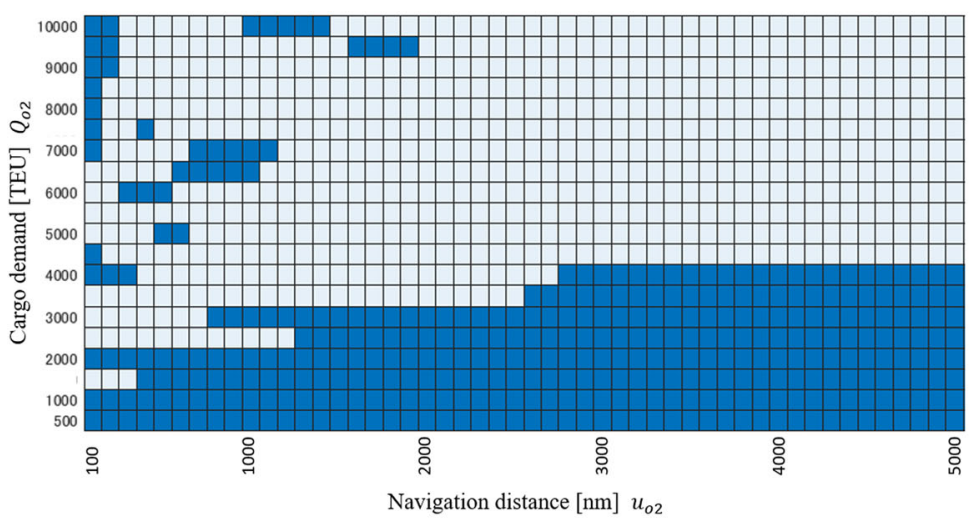

(c) Long distance case $\left(u_{o 1}=8000 \mathrm{~nm}, Q_{o 1}=2500 \mathrm{TEU}\right), \delta_{h d}=5$

$$
G C_{o 2}^{T S}>G C_{o 2}^{D R} \quad \square G C_{o 2}^{T S}<G C_{o 2}^{D R}
$$

(Dark blue cells depict cost-effectiveness of direct shipment)

Fig. 4 Results of comparison of the shippers' generalized cost in three cases

Destinations 1 and 2 and the economy of density applies from the origin to hub port, the generalized cost for transshipment is lower in some cases. Therefore, direct shipment is highly cost-effective under conditions where the volume of aggregated cargo is too small for the economy of density to apply effectively. This indicates the significance of the port's competitiveness as a hub for aggregating cargo in transshipment, ensuring costeffectiveness. 


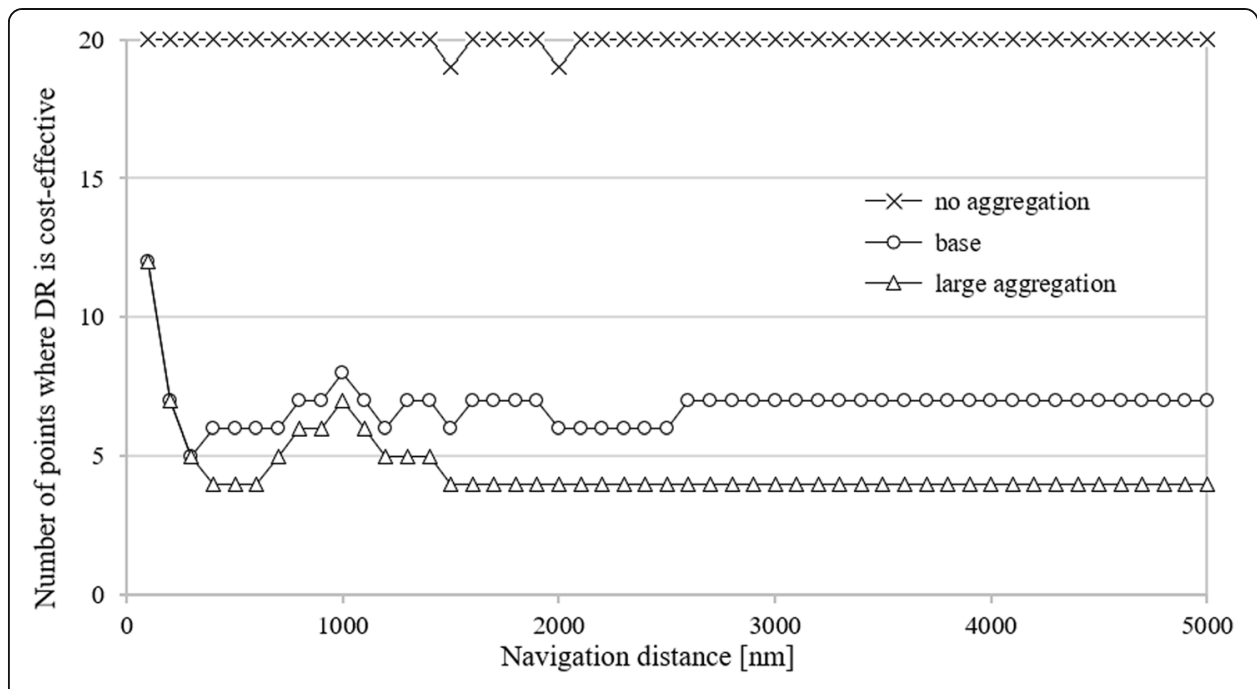

Fig. 5 Results of modifying the volume of cargo aggregated in transshipment

With regard to the impact of distance on the network, direct shipment becomes costeffective at several points at $2000 \mathrm{~nm}$ in over 4000 TEU, as illustrated in Figs. 4 and 5 . This is due to the configuration conditions of each route, such as frequency and the vessel size deployed by shipping lines. Figure 6 confirms this, displaying the frequency of each route from $100 \mathrm{~nm}$ to $2000 \mathrm{~nm}$ in 7000 TEU for the short distance case. Figure 6 exhibits the frequency and vessel size changing at the points in which the costeffectiveness of the network changes, that is, $100-200 \mathrm{~nm}, 600-700 \mathrm{~nm}$, and 1100 $1200 \mathrm{~nm}$. This indicates that the cost-effectiveness of both direct shipment and transshipment depends on their configuration. Direct shipment is not cost-effective in cases with larger vessel size and low frequency, such as over $1200 \mathrm{~nm}$. Larger vessels are deployed for longer navigation distances owing to higher introduction costs, such as vessel costs, and lower fuel cost per TEU, so that shipping lines deploy the larger vessel with low frequency. Conversely, smaller vessels with higher frequency is deployed in short distances and direct shipping can be more cost-effective for shippers. Additionally, the calculation of cost-effectiveness of transshipment depends on its configuration.

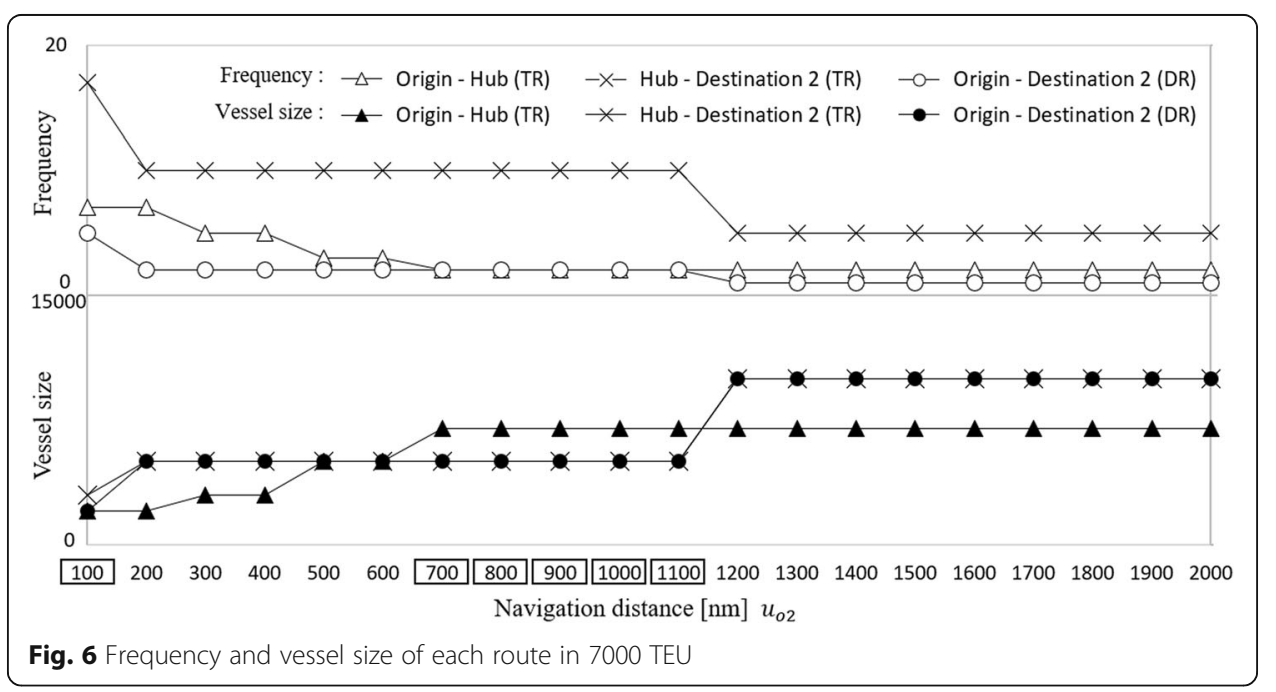


As the trends of changes in each shipment system are different, especially from the origin to the hub port, direct shipment is not always more cost-effective for short distances. The difference in the changes can cause uneven cost-effectiveness of direct shipment and transshipment, resulting in the mottled pattern illustrated in Fig. 4.

\section{Sensitivity analysis}

In the above simulations, we mainly focus on the cargo demand and distance. Bunker price and the value of the shippers' time are set as inputs with fixed values. However, these factors can affect the comparison between direct shipment and transshipment. For example, a higher bunker price may increase costs, particularly for transshipment, due to the longer total navigation distance between the origin and destination ports, as the hub port is transshipped. Additionally, bunker price is known to have high variability. In contrast, shippers with a higher value of time may prefer direct shipment due to its shorter lead time for transport between the origin and destination port. Therefore, we conduct a sensitivity analysis focused on these two factors, to observe any significant change in the key output. The scenarios considered include two cases of the bunker price decreasing or increasing in the short distance case and $\delta_{h d}=5$ as a low or high bunker price, and two cases of the value of time decreasing or increasing in the short distance case and $\delta_{h d}=5$ as a low or high value of time. Table 2 presents the detailed conditions of these scenarios.

Figure 7 illustrates the results of the sensitivity analysis with regard to the bunker price and value of time. The vertical line indicates the number of points in which the generalized cost for direct shipment is lower than that for transshipment, similar to the comparison illustrated in Fig. 5. As exhibited in Fig. 7, the shapes of the trends of changes in the bunker price are almost the same, and the peaks of the trends shift slightly to the right as the bunker price decreases. This indicates that a decrease in the bunker price can expand the area where direct shipment can be more cost-effective. However, the changes in the bunker price do not affect the results discussed in Cargo Demand section, that is, direct shipment may be more cost-effective for short distances. The results for the value of time are almost the same (Fig. 7), with a few different points, especially for a low value of time. This implies that the difference in the value of time for direct shipment and transshipment does not influence cost-effectiveness significantly. Changes in the value of time do not affect the results discussed in Cargo Demand section. Thus, while changes in the bunker price and value of time can affect the comparison between direct shipment and transshipment, they do not affect the results significantly.

\section{Conclusions}

This study aims to examine the conditions that influence the choice between direct shipment and transshipment, focusing on two factors: geographical distance and demand. We develop a two-stage model comprising shipping lines and shippers, and apply it to a virtual maritime network with one origin, two destination ports, and one hub port. The conditions of one of the destination ports in the virtual network are modified slightly, while those of the other are significantly modified. The cases in which the shippers' generalized cost for direct shipment is lower than that incurred in the destination, with slightly- 
Table 2 Detailed conditions of the scenarios for sensitivity analysis

\begin{tabular}{lll}
\hline & Bunker price [USD/ton] & Value of time [JPY/hour] \\
\hline Base & 387.5 & 2200 \\
Low bunker price & 250.0 & 2200 \\
High bunker price & 500.0 & 2200 \\
Low value of time & 387.5 & 1700 \\
High value of time & 387.5 & 2700 \\
\hline
\end{tabular}

modified conditions, are considered more cost-effective. As previous studies do not analyze factors other than cargo demand, this study contributes to the literature by analyzing the both cargo demand and geographical conditions in the comparison between direct shipment and transshipment and deriving the following results.

First, geographical changes in another destination port with cargo from the same origin do not influence the shippers' choice of a network. Although the distance of one destination port may affect the position of the hub port, it does not affect the other significant configuration, that of Destination 2, including the frequency of the originhub and hub-destination. The geographical changes in the other destination port do not influence the cost-effectiveness of direct shipment or transshipment.

Second, in cases of a large volume of aggregated cargo, the costs of shipping lines decrease, and the economy of density lowers the generalized cost for transshipment. The port's competitiveness as a hub, indicating the cargo volume aggregated in transshipment, is essential for examining cost-effectiveness. Direct shipment is more cost-effective when the hub port exhibits low competitiveness.

Finally, the comparison between the cost-effectiveness of direct shipment and transshipment depends on the configuration of each network, especially in terms of frequency and the vessel size. Smaller vessel with higher frequency is deployed by shipping lines in short distances. Direct shipment can be more cost-effective for shippers in short distances.

A major limitation of this study is that the virtual network did not completely represent the actual maritime network. For example, although we consider the

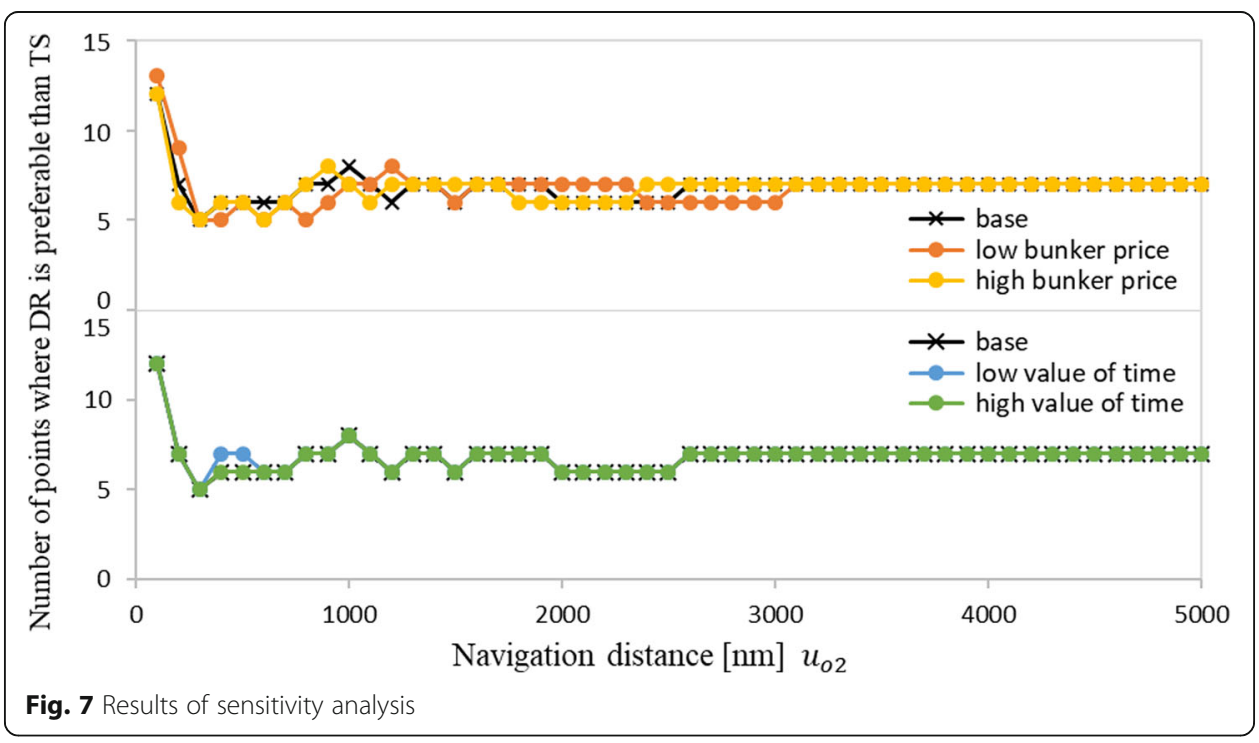


monetary and time cost as the generalized cost, the service quality, such as delay and port infrastructure, might affect the competition between direct shipment and transshipment. One needs to consider non-quantitative criteria for port selection by applying observed data. These aspects should be investigated in future research.

\section{Abbreviations}

DR: Direct shipment; JPY: Japanese yen; MLIT: Ministry of Land, Infrastructure, Transport and Tourism; nm: Nautical miles; OD: Origin-Destination; TEU: Twenty-foot equivalent unit; TS: Transshipment; USD: United States dollars; WAVE: Waterfront Vitalization and Environment Research Foundation

\section{Acknowledgements}

Not applicable.

\section{Authors' contributions}

All authors contributed jointly to the manuscript, and read and approved the final manuscript.

Funding

This work was supported by JSPS KAKENHI [grant number 20 K04732].

\section{Availability of data and materials}

The datasets used and analyzed during the current study are available from the corresponding author on reasonable request.

\section{Declarations}

\section{Competing interests}

The authors declare that they have no competing interests.

\section{Author details}

${ }^{1}$ Department of Transdisciplinary Science and Engineering, Tokyo Institute of Technology, Tokyo, Japan. ${ }^{2}$ Department of Systems Innovation, School of Engineering, The University of Tokyo, Tokyo, Japan.

Received: 19 November 2020 Accepted: 15 March 2021

Published online: 12 May 2021

\section{References}

Chang Y-T, Lee S-Y, Tongzon UL (2008) Port selection factors by shipping lines: different perspectives between trunk liners and feeder service providers. Mar Policy 32(3):877-885. https://doi.org/10.1016/S0966-6923(00)00010-7

Ducruet C, Notteboom TE (2012) Developing liner service networks in container shipping. In: Song DW, Panayides P (eds) Maritime logistics: a complete guide to effective shipping and port management. Kogan Page, London

Francis G, Dennis N, Ison S, Humphreys I (2007) The transferability of the low-cost model to long-haul airline operations. Tour Manag 28(2):391-398. https://doi.org/10.1016/j.tourman.2006.04.014

Gohomene DA, Yang ZI, Bonsal S, Maistralis E, Wang J, Li KX (2016) The attractiveness of ports in West Africa: some lessons from shipping lines' port selection. Growth Chang 47(3):416-426. https://doi.org/10.1111/grow.12133

Hsu C-I, Hsieh Y-P (2005) Direct versus terminal routing on a maritime hub-and-spoke container network. J Mar Sci Technol 13:209-217

Hsu C-I, Hsieh Y-P (2007) Routing, ship size, and sailing frequency decision-making for a maritime hub-and-spoke container network. Math Comput Model 45(7-8):899-916. https://doi.org/10.1016/j.mcm.2006.08.012

Kavirathna CA, Kawasaki T, Hanaoka S (2018) Transshipment hub port competitiveness of the port of Colombo against the major southeast Asian hub ports. Asian J Shipping Logist 34(2):71-82. https://doi.org/10.1016/j.ajsl.2018.06.004

Kim H, Son D, Yang W, Kim J (2019) Liner ship routing with speed and fleet size optimization. KSCE J Civ Eng 23(3):13411350. https://doi.org/10.1007/s12205-019-0564-6

Ministry of Land, Infrastructure, Transport and Tourism (MLIT) of Japan. Data from: Nationwide Flow Survey of Export-Import Container Cargos data set. 2018

Morrell P (2008) Can long-haul low-cost airlines be successful? Res Transp Econ 24(1):61-67. https://doi.org/10.1016/j.retrec.2 009.01 .003

Ng AKY, Kee JKY (2008) The optimal ship sizes of container liner feeder services in Southeast Asia: a ship operator's perspective. Marit Pol Mgmt 35(4):353-376. https://doi.org/10.1080/03088830802198167

Notteboom TE (2011) An application of multi-criteria analysis to the location of a container hub port in South Africa. Marit Pol Mgmt 38(1):51-79. https://doi.org/10.1080/03088839.2010.533710

Notteboom TE, Parola F, Satta G (2019) The relationship between transhipment incidence and throughput volatility in north European and Mediterranean container ports. J Transp Geogr 74:371-381. https://doi.org/10.1016/j.jtrangeo.2019.01.002

Notteboom TE, Vernimmen B (2009) The effect of high fuel costs on liner service configuration in container shipping. J Transp Geogr 17(5):325-337. https://doi.org/10.1016/j.jtrangeo.2008.05.003

O'Kelly ME, Miller HJ (1994) The hub network design problem: a review and synthesis. J Transp Geogr 2(1):31-40. https://doi. org/10.1016/0966-6923(94)90032-9

Ship \& Bunker. (2019) Global 20 Ports Average. https://shipandbunker.com/prices/av/global/av-g20-global-20-ports-average. Accessed 05 September 2019

Sun Z, Zheng J (2016) Finding potential hub locations for liner shipping. Transp Res Part B Method 93:750-761. https://doi. org/10.1016/j.trb.2016.03.005 
Tran NK (2011) Studying port selection on liner routes: an approach from logistics perspective. Res Transp Econ 32(1):39-53. https://doi.org/10.1016/j.retrec.2011.06.005

Veldman S, Garcia-Alonso L, Liu M (2016) Testing port choice models using physical and monetary data: a comparative case study for the Spanish container trades. Marit Pol Mgmt 43(4):495-508 https://doi.org/10.1080/03088839.2015.1099754

Wang H, Meng Q, Zhang X (2014) Game-theoretical models for competition analysis in a new emerging liner container shipping market. Transp Res Part B Method 70:201-227. https://doi.org/10.1016/j.trb.2014.09.006

Wang S, Meng Q (2012) Sailing speed optimization for container ships in a liner shipping network. Transp Res E Logist Transp Rev 48(3):701-714. https://doi.org/10.1016/j.tre.2011.12.003

Wang S, Wang H, Meng Q (2015) Itinerary provision and pricing in container liner shipping revenue management. Transp Res E Logist Transp Rev 77:135-146. https://doi.org/10.1016/j.tre.2014.06.020

Waterfront Vitalization and Environment Research Foundation (WAVE) (2011). Handbook for the evaluation of port investment. WAVE, Tokyo. (In Japanese)

Wilmsmeier G, Notteboom TE (2011) Determinants of liner shipping network configuration: a two-region comparison. GeoJournal 76(3):213-228. https://doi.org/10.1007/s10708-009-9333-2

\section{Publisher's Note}

Springer Nature remains neutral with regard to jurisdictional claims in published maps and institutional affiliations.

Submit your manuscript to a SpringerOpen ${ }^{\circ}$ journal and benefit from:

- Convenient online submission

- Rigorous peer review

- Open access: articles freely available online

- High visibility within the field

- Retaining the copyright to your article 